\title{
Capability Assessment Model for Software Outsourcing Service Providers Based on Interval Evidential Reasoning
}

\author{
Sheng-Qun Chen \\ Fujianjiangxia University, Fuzhou 350108, PR China \\ csq@fjjxu.edu.cn
}

\begin{abstract}
Keywords: Software outsourcing, Service provider, Interval value, Evidential reasoning
Abstract. An enterprise may benefit from software business outsourcing depending on the suitability of the outsourcing service provider. This research addresses the assessment of the contracting capability of software outsourcing vendors and proposes a decision-making model based on Interval Evidential Reasoning (IER). Firstly, a capability assessment index system for software outsourcing vendors is developed. The idea of transforming different types of assessment information into evidence probability is presented and an assessment model based on IER is established. Finally, the feasibility and validity of this approach is demonstrated by an example calculation.
\end{abstract}

\section{Introduction}

Software business outsourcing refers to the software requirement activity whereby software enterprises subcontract a software project, either entirely or in part, to software outsourcing service providers. Software business outsourcing may yield a number of benefits, namely, it may allow the contract-issuing party to focus on enterprise core competency business to a greater extent, and it may lower the cost of software projects. However, the failure rate of software outsourcing projects continues to remain very high. One of the key reasons for failure is the blind selection of software outsourcing service providers. Therefore, the outsourcing industry urgently demands a set of scientific rules and a mature capability assessment model to enable them to assess software outsourcing service providers. Currently, researchers mainly employ a quantitative approach to address the issue of capability assessment of outsourcing service providers. For example, a decision-making model for shipbuilding enterprises to select IT outsourcing service providers was proposed by $\mathrm{Hu}$ et al. [1]; a study on capability assessment methods for IT outsourcing providers based on eSCM-SP was conducted by Luan et al. [2]; a fuzzy attribute measurement approach was employed by Zhang et al. [3] to address the assessment issues for core competences of IT outsourcing service providers. These scientific assessment models provide a theoretical basis and methodological support for selecting suitable software outsourcing service providers. However, due to the fact that it is difficult to identify objective information and the subjective judgment is constrained, the assessment information obtained is normally characterized by interval values or even unknown values, which leads to the inapplicability of these methods. Thus, a novel approach is required to address these issues.

Evidence theory $[4,5]$ was originally developed by Dempster and later extended and refined by Shafer. Evidential reasoning (ER) based on both decision theory and DS theory was proposed by Yang and Singh [6]. The ER approach has been widely applied to multiple attribute decision making (MADM) problems with uncertainty in business performance assessment [7, 8], environmental impact assessment [9], organizational self-assessment [10], safety analysis [11, 12], and group decision analysis [13]. That is to say, ER is a powerful and flexible mathematical tool for processing uncertain information. The availability of information of this nature in multiple formats, such as exact values and interval values, when assessing software outsourcing service providers prompted us to develop the Interval Evidential Reasoning (IER) to address assessment related issues. 


\section{Assessment Index System}

A rational assessment index system is of great significance for increasing the success rate of software outsourcing projects. Based on a reported selection model [14], the following capability assessment index system for software outsourcing service providers is proposed:

- Fundamental qualities: including enterprise scale, financial standing, and human resources;

- Technical level: consisting of technical maturity, project experience, and technical innovation;

- Track records: comprising brand familiarity and historical reputation;

- Management capabilities: including people management, quality management, progress management, contract management, and cultural compatibility.

The assessment index system for software business outsourcing service providers is presented schematically in Fig.1.

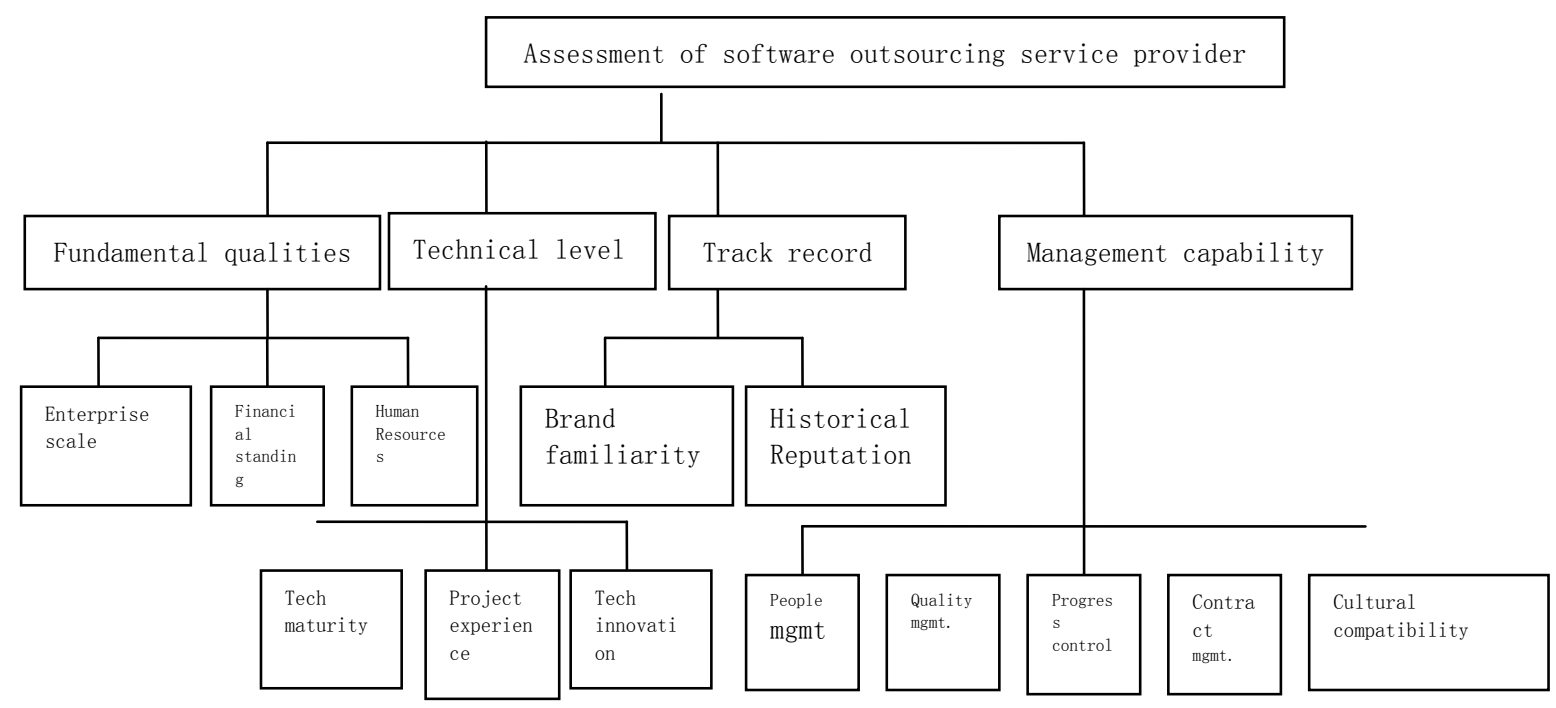

Fig.1 Index hierarchy for software business outsourcing service provider

\section{Assessment Model}

This paper proposes the IER approach as the basic tool to address the issue of capability assessment of software outsourcing service providers. The main objective of this approach is to transform the assessment information of various indexes into probabilistic representations required of ER. Besides, an interval evidential fusion model is established for capability assessment, and this enables the final decision-making scheme to be obtained. Before the assessment model is presented, the following related definition is given:

Definition 1 Let $Y_{1}, \ldots Y_{N}$ denote the standard values corresponding to assessment ranks $H_{1}, \ldots, H_{N}$, and let $\left(H_{i}, \alpha_{i}\right)$ represent the degree of belief for the assessment value at rank $H_{i}$ to be $\alpha_{i}$; thus, $\alpha_{i}$ is referred to as the rank belief degree at rank $H_{i}$, besides, $\left\{\left(H_{1}, \alpha_{1}\right), \ldots,\left(H_{N}, \alpha_{N}\right)\right\}\left(\sum_{i=1}^{N} \alpha_{i} \leq 1\right)$ is referred to as the structure of rank belief degrees.

In terms of the information on linguistic values, when $y$ is the standard linguistic value for the assessment $\operatorname{rank} H_{n}$, then the probability of the assessment value $y$ at assessment $\operatorname{rank} H_{n}$ equals 1 , thus $y$ is transformed into the corresponding rank belief degree $\left\{\left(H_{n}, 1\right)\right\}$;

According to previous research [15], information on the exact values and interval values will be transformed into the corresponding rank belief degrees. 
As to the unknown values, it is obvious that the transformed respective rank belief degrees also remain unknown, namely, they fall over any location of rank $H_{1}, H_{2}, \ldots, H_{N}$ with $100 \%$ degree of belief, thus, making their corresponding rank degree of belief to be $\left\{\left(\left(H_{1}, H_{2}, \ldots, H_{N}\right), 1\right)\right\}$.

Evidential reasoning (ER) is a reasoning approach capable of processing uncertainty, and allows the decomposition of evidence into sub-evidence. Moreover, following the corresponding processing of sub-evidence, the solution of the entire problem may be obtained by means of the ER combination rule; hence, ER is also a decision-making approach. Our previous report about IER [15] concerned a study of the application of interval-value multi-attribute decision-making to the IER approach. Let the assessment rank $H_{1}, \ldots, H_{N}$ represent the evidence identification framework, then the optimal evidence fusion model is established as follows:

$$
\begin{aligned}
M a x / \min & f\left(H_{1}, \ldots, H_{N}\right)=\sum_{n=1}^{N}\left[\beta_{n, 12 \ldots L} \cdot U\left(H_{n}\right)\right]+\left(1-\sum_{n=1}^{N} \beta_{n, 12 \ldots L}\right) \cdot \sum_{n=1}^{N} U\left(H_{n}\right) / N \\
\text { s.t. } \quad & \beta_{n, 12 \ldots L}=\frac{m_{n, 12 \ldots L}}{1-m_{H, 12 \ldots L}}, \quad n=1, \ldots, N, \\
& m_{12 \ldots L}=m_{1} \oplus m_{2} \ldots \oplus m_{L} \\
& m_{i}: m_{n, i}=w_{i} \beta_{n, i}, \bar{m}_{H, i}=1-w_{i}, m_{H, i}=w_{i} \beta_{H, i}, \quad n=1, \ldots, N ; \quad i=1, \ldots, L, \\
& \beta_{n, i}^{-} \leq \beta_{n, i} \leq \beta_{n, i}^{+}, \widetilde{\beta_{H, i}} \leq \widetilde{\beta_{H, i}} \leq \widehat{\beta_{H, i}}, \quad n=1, \ldots, N ; \quad i=1, \ldots, L, \\
& \sum_{n=1}^{N} \beta_{n, i}+\widetilde{\beta_{H, i}}=1, \quad i=1, \ldots L .
\end{aligned}
$$

where, $\beta_{n, 12 \ldots L}$ denotes the degree of belief for rank $n$ following the fusion of evidence $1,2, \ldots, L$, $\left(1-\sum_{n=1}^{N} \beta_{n, 12 \ldots L}\right)$ represents the degree of belief for unknown information after the fusion, $U\left(H_{n}\right)$ denotes the utility value of rank $H_{n}$, and $f\left(H_{1}, \ldots, H_{N}\right)$ stands for the mean utility value of rank belief degrees.

The meanings of various formulae for the above model are given below: Eq. 1 is an objective function, which solves the maximum value $f^{+}$and minimum $f^{-}$, thereby providing the utility value of the alternative scheme $f \in\left[f^{-}, f^{+}\right]$; Eq. 2 represents that the Basic Probability Assignment (BPA) values of fused evidence are transformed into rank degrees of belief; Eq. 3 denotes that the evidence with regard to various attributes is fused by means of the ER combination rule, thereby providing the BPA values of fused evidence; Eq. 4 represents that prior to the fusion, rank degrees of belief are transformed into the BPA of evidence; Eq. 5 denotes the interval values of assessment degrees of belief; Eq. 6 represents that the sum of assessment degrees of belief for different ranks is equal to 1 .

\section{Analysis by an Example Calculation}

In this section, an example is provided to demonstrate the proposed IER approach. A high-tech enterprise in China publishes a software outsourcing project. SC1 and SC2 are service providers willing to undertake this project. Thus, in compliance with the above indexes, the contract-issuing party conducts an assessment of service providers SC1 and SC2, of which the assessment index values and corresponding weights are presented in Table 1. 
Table 1. Assessment index values and corresponding weights of the two service providers

\begin{tabular}{|c|c|c|c|}
\hline Basic criteria & Sub-index & SC1 & SC2 \\
\hline \multirow{3}{*}{ Fundamental qualities (0.25) } & Enterprise scale (sq.m.) (0.35) & 180 & 320 \\
\cline { 2 - 4 } & Financial standing (ten thousand CNY) (0.30) & {$[550,680]$} & {$[480,630]$} \\
\cline { 2 - 4 } Technical level (0.25) & Human resources (No. of people) $(0.35)$ & 96 & 145 \\
\cline { 2 - 4 } & Technical maturity (\%)(0.50) & {$[70,76]$} & - \\
\cline { 2 - 4 } Track record (0.25) & Project experience (0.30) & {$[35,39]$} & Poor \\
\hline & Technical innovation (\%)(0.20) & {$[52,68]$} & {$[42,52]$} \\
\cline { 2 - 4 } & Brand familiarity (\%)(0.40) & 85 & 93 \\
\hline \multirow{3}{*}{ Management capability (0.25) } & previous three years)(0.60) & 60 & 45 \\
\cline { 2 - 4 } & People management (staff turnover/yr)(0.30) & Good & Normal \\
\cline { 2 - 4 } & Quality management (0.15) & {$[70,79]$} & {$[55,68]$} \\
\cline { 2 - 4 } & Contract management (signed contracts/yr)(0.15) & 86 & 72 \\
\cline { 2 - 4 } & Cultural compatibility ratio (\%)(0.15) & - & {$[32,44]$} \\
\hline
\end{tabular}

In order to identify a comparatively satisfactory service provider, the following detailed solving steps are given based on the approach proposed in this paper:

Step 1: Based on the preferences of decision makers, a set of assessment ranking criteria and utilities values is compiled. These criteria are provided in Table 2.

Table 2. Assessment ranking criteria and utility values

\begin{tabular}{|c|c|c|c|c|c|c|}
\hline Basic criteria & Sub-index & $H_{l}$ & $\mathrm{H}_{2}$ & $\mathrm{H}_{3}$ & $\mathrm{H}_{4}$ & $\mathrm{H}_{5}$ \\
\hline \multirow{3}{*}{ Fundamental qualities } & Enterprise scale & 50 & 150 & 200 & 250 & 350 \\
\hline & Financial standing & 300 & 500 & 600 & 700 & 800 \\
\hline & Human resources & 30 & 90 & 120 & 150 & 180 \\
\hline \multirow{3}{*}{ Technical level } & Technical maturity & 20 & 40 & 50 & 60 & 100 \\
\hline & Project experience & Very poor & Poor & Normal & Good & Very good \\
\hline & Technical innovation & 0 & 20 & 40 & 60 & 100 \\
\hline \multirow{2}{*}{ Track record } & Brand familiarity & 10 & 30 & 50 & 70 & 100 \\
\hline & Historical reputation & 60 & 70 & 80 & 90 & 100 \\
\hline \multirow{5}{*}{ Management capability } & People management & 10 & 30 & 50 & 70 & 90 \\
\hline & Quality management & Very poor & Poor & Normal & Good & Very good \\
\hline & Progress management & 0 & 40 & 60 & 80 & 100 \\
\hline & Contract management & 0 & 30 & 50 & 70 & 100 \\
\hline & $\begin{array}{c}\text { Cultural } \\
\text { compatibility ratio }\end{array}$ & 10 & 30 & 50 & 70 & 100 \\
\hline
\end{tabular}

Step 2: Based on the probabilistic method of transforming information assessment values into evidence, the degrees of belief for the assessment ranking are thereby established.

Table 3. Assessment rankings determined for each service provider

\begin{tabular}{|c|c|c|c|}
\hline Basic criteria & Sub-index & $\mathrm{SC} 1$ & SC2 \\
\hline \multirow{3}{*}{$\begin{array}{c}\text { Fundamental } \\
\text { qualities }\end{array}$} & $\begin{array}{c}\text { Enterprise } \\
\text { scale }\end{array}$ & $\left\{\left(H_{2}, 0.4\right),\left(H_{3}, 0.6\right)\right\}$ & $\left\{\left(H_{4}, 0.3\right),\left(H_{5}, 0.7\right)\right\}$ \\
\hline & $\begin{array}{c}\text { Financial } \\
\text { standing }\end{array}$ & $\begin{array}{c}\left\{\left(H_{2},[0,0.192],\left(H_{3},[0.315,1]\right)\left(H_{4},[0,0.49\right.\right.\right. \\
2])\}\end{array}$ & $\begin{aligned} &\left\{\left(H_{1},[0,0.013]\right),\left(H_{2},[0.12,0.8]\right),\left(H_{3}\right.\right. \\
&\left.,[0.14,0.86]),\left(H_{4},[0,0.06]\right)\right\}\end{aligned}$ \\
\hline & $\begin{array}{c}\text { Human } \\
\text { resources }\end{array}$ & $\left\{\left(H_{2}, 0.8\right),\left(H_{3}, 0.2\right)\right\}$ & $\left\{\left(H_{3}, 0.166\right),\left(H_{4}, 0.833\right)\right\}$ \\
\hline \multirow{3}{*}{$\begin{array}{l}\text { Technical } \\
\text { level }\end{array}$} & $\begin{array}{l}\text { Technical } \\
\text { maturity }\end{array}$ & $\left\{\left(H_{4},[0.6,0.75]\right),\left(H_{5},[0.25,0.4]\right)\right\}$ & $\left.\left\{\left(H_{1}, H_{2}, H_{3}, H_{4}, H_{5}\right), 1\right)\right\}$ \\
\hline & $\begin{array}{c}\text { Project } \\
\text { experience }\end{array}$ & $\left\{\left(H_{3}, 1.0\right)\right\}$ & $\left\{\left(H_{2}, 1.0\right)\right\}$ \\
\hline & $\begin{array}{c}\text { Technical } \\
\text { innovation }\end{array}$ & $\left\{\left(H_{2},[0.05,0.25]\right),\left(H_{3},[0.75,0.95]\right)\right\}$ & $\left\{\left(H_{3},[0.4,0.9]\right),\left(H_{4},[0.1,0.6]\right)\right\}$ \\
\hline \multirow{2}{*}{ Track record } & $\begin{array}{c}\text { Brand } \\
\text { familiarity }\end{array}$ & $\left\{\left(H_{3},[0.1,0.9]\right),\left(H_{4},[0.1,0.9]\right)\right\}$ & $\left\{\left(H_{3},[0.2,0.75]\right),\left(H_{4},[0.25,0.8]\right)\right\}$ \\
\hline & $\begin{array}{l}\text { Historical } \\
\text { reputation }\end{array}$ & $\left\{\left(H_{3}, 0.5\right),\left(H_{4}, 0.5\right)\right\}$ & $\left\{\left(H_{4}, 0.3\right),\left(H_{5}, 0.7\right)\right\}$ \\
\hline $\begin{array}{c}\text { Management } \\
\text { capability }\end{array}$ & $\begin{array}{c}\text { Staff } \\
\text { management }\end{array}$ & $\left\{\left(H_{3}, 0.5\right),\left(H_{4}, 0.5\right)\right\}$ & $\left\{\left(H_{2}, 0.25\right),\left(H_{3}, 0.75\right)\right\}$ \\
\hline
\end{tabular}




\begin{tabular}{|c|c|c|c|}
\hline & $\begin{array}{c}\text { Quality } \\
\text { management }\end{array}$ & $\left\{\left(H_{4}, 1.0\right)\right\}$ & $\left\{\left(H_{3}, 1.0\right)\right\}$ \\
\cline { 2 - 4 } & $\begin{array}{c}\text { Progress } \\
\text { management }\end{array}$ & $\left\{\left(H_{3},[0.05,0.5]\right)\left(H_{4},[0.5,0.95]\right)\right\}$ & $\left\{\left(H_{2},[0,0.096]\right.\right.$, \\
\cline { 2 - 4 } & $\begin{array}{c}\text { Contract } \\
\text { management }\end{array}$ & $\left\{\left(H_{4}, 0.466\right),\left(H_{5}, 0.533\right)\right\}$ & $\left\{\left(H_{4}, 0.933\right),\left(H_{5}, 0.067\right)\right\}$ \\
\cline { 2 - 4 } & $\begin{array}{c}\text { Cultural } \\
\text { compatibility } \\
\text { ratio }\end{array}$ & $\left.\left\{\left(H_{1}, H_{2}, H_{3}, H_{4}, H_{5}\right), 1\right)\right\}$ & $\left\{\left(H_{2},[0.3,0.9]\right)\left(H_{3},[0.1,0.7]\right)\right\}$ \\
\hline
\end{tabular}

Step3: based on solving Eqs. 1-6 of the model, the final utility values of SC1 and SC2 are presented as follows: $\mathrm{SC} 1 \in[0.532335,0.5730509]$; $\mathrm{SC} 2 \in[0.5664709,0.608773]$. Generally, the mean utility value is employed to identify the respective utility value of a service provider. Thus, SC2 is superior to $\mathrm{SC} 1$; therefore, service provider SC2 is preferred.

\section{Conclusion}

This paper proposes an approach whereby uncertain information with respect to capability assessment of software outsourcing service providers is transformed into probabilistic representations of evidence. Moreover, an IER-based optimization combination model is established to facilitate decision making regarding the selection of software outsourcing service providers. It presents a simple and rational approach, the validity and feasibility of which are verified by an example calculation. Admittedly, some issues subject to further research continue to exist: in particular, the probability of transforming information into evidence needs to be further simplified.

\section{Acknowledgments and Funding}

Funded projects: National Natural Science Foundation of China (No. 71371053, 71403055); Youth Fund for Projects of Humanities and Social Sciences under the Ministry of Education, China (Grant No. 16YJC630008); Fujian Province Natural Science Foundation Project (Grant No. 2015J01279); The Education and Scientific Research Project for Young Teachers of Fujian province (Grant No. JA14322); The Scientific Research Project for Young Scholars of Fujian Jiangxia University (Grant No. JXZ2014003); The Education and Teaching Reform Project of Fujian Jiangxia University (Grant No. J2015A1004).

\section{References}

[1] W. Hu, E.L. Li, D.D. Shi, The decision making model for shipbuilding enterprises to select IT outsourcing service providers, Statistics and Decision. 22 (2012) 49-51.

[2] D.Q. Luan, W. Chang, K.J. Hu, Study on the Capability Improvement and Measurement of IT Outsourcing Provider Based on eSCM-SP, Comput. Sci. 34 (2007), 286-288

[3] S.H. Zhang, Z.Q. Zhu, W.J. Huang, The evaluation model for core competence of IT outsourcing vendor based on fuzzy attribute measure, Mathematics in Practice and Theory 41 (2011) 22-29.

[4] A.P. Dempster, Upper and lower probabilities induced by a multivalued mapping, Ann. Math. Stat. 38 (1967) 325-339.

[5] G. Shafer, A mathematical theory of evidence, Princeton University Press, Princeton, 1976.

[6] J.B. Yang, G. Singh Madan, An evidential reasoning approach for multiple-attribute decision making with uncertainty, IEEE Trans. Syst. Man Cybern. 24 (1994) 1-18.

[7] D.L. Xu, J.B. Yang, Intelligent decision system for self-assessment, Journal of Multi-Criteria Decision Analysis 12 (2003) 43-60. 
[8] D.L. Xu, J.B. Yang, Intelligent decision system based on the evidential reasoning approach and its applications, J. Telecomm. Inform. Technol. 5 (2005) 73-80.

[9] J.B. Yang, D.L. Xu, Proc. Conf. Intelligent decision system for supplier assessment (DSS2004), Italy, 2004, pp. 847-860.

[10] X.B Liu, F. Pei, J.B. Yang, S.L. Yang, An MAGDM approach combining numerical values with uncertain linguistic information and its application in evaluation of R \& D projects, Int. J. Comput. Intell. Syst. 3 (2010) 575-589.

[11] Y.M. Wang, J.B. Yang, D.L. Xu, Environmental impact assessment using the evidential reasoning approach, Eur. J. Oper. Res. 174 (2006) 1885-1913.

[12] C.H.R. Siow, A new modeling framework for organizational self-assessment: development and application, Quality Management Journal 8 (2001) 34-47.

[13] T. Mahmud, K.N. Rahman, M.S. Hossain, Evaluation of job offers using the evidential reasoning approach, GJSFR-D: Agriculture and Veterinary 13 (2013) 34-44.

[14]R. Li, N. Wang, A study on the selection model for software business outsourcing service providers, Science and Technology Management Research 3 (2008) 111-114.

[15] S.Q. Chen, Y.M. Wang, H.L. Shi, The fusion method for rank belief degrees based on multi-attribute matching decision-making, J. Syst. Eng. 30 (2015) 25-33. 